\title{
Comparison Between Three Chromatographic (GC-ECD, GC-PFPD and GC-ITD-MS) Methods and a UV-Vis Spectrophotometric Method for the Determination of Dithiocarbamates in Lettuce
}

\author{
Ionara R. Pizzutti, *,a André de Kok, ${ }^{b}$ Rosselei C. da Silva ${ }^{a, c}$ and Graciele N. Rohers ${ }^{a}$ \\ ${ }^{a}$ Centro de Pesquisa e Análise de Resíduos e Contaminantes (CEPARC), Departamento de Química, \\ Universidade Federal de Santa Maria, 97105-900 Santa Maria-RS, Brazil \\ ${ }^{b}$ NVWA-Netherlands Food and Consumer Product Safety Authority, Chemistry Laboratory, \\ $R \& D$ Group, National Reference Laboratory (NRL) for Pesticide Residues in Food and Feed, \\ Wageningen, The Netherlands \\ cUniversidade Regional Integrada do Alto Uruguai e das Missões, \\ 98400-000 Frederico Westphalen-RS, Brazil
}

\begin{abstract}
The purpose of this study was to compare the performance of gas chromatographic with electron capture detector, pulsed flame photometric detector and mass spectrometry (GC-ECD, GC-PFPD and GC-MS) and UV-Vis spectrophotometric methods, based on acidic hydrolysis with tin(II) chloride of dithiocarbamate and analysis of the evolved $\mathrm{CS}_{2}$. For the validation studies were assessed linearity, limit of detection (LOD), limit of quantification (LOQ), accuracy and precision. Recovery experiments were performed at 0.05 and 0.4 (chromatographic method) and $0.4,0.8$ and $2.0 \mathrm{mg} \mathrm{CS}_{2} \mathrm{~kg}^{-1}$ (UV-Vis spectrophotometric method). The analytical curves were linear from 0.08 to $2.0 \mu \mathrm{g} \mathrm{CS}_{2} \mathrm{~mL}^{-1}$ (chromatographic method) and from 0.4 to $2.2 \mu \mathrm{g} \mathrm{mL} \mathrm{m}^{-1}$ and from 2.2 to $8.9 \mu \mathrm{g} \mathrm{CS} \mathrm{mL}^{-1}$ (both with $\mathrm{r}^{2}>0.995$ ) (UV-Vis spectrophotometric method). Method LODs were 0.01 and $0.28 \mathrm{mg} \mathrm{CS}_{2} \mathrm{~kg}^{-1}$ and LOQs were 0.02 and $0.4 \mathrm{mg} \mathrm{CS}_{2} \mathrm{~kg}^{-1}$ for the chromatographic and spectrophotometric methods, respectively. Acceptable accuracy was obtained for both methods (RSDs $<15.9 \%$ and recoveries from $87.7-107.4 \%$ ). There was no significant difference between the techniques and detectors employees.
\end{abstract}

Keywords: dithiocarbamate, fungicide, lettuce, gas chromatography, UV-Vis spectrophotometry

\section{Introduction}

Dithiocarbamates (DTCs) are important fungicides and the most widely used group of pesticides in agriculture, due to their high efficiency for the control of fungal and bacterial pathogens, low production costs and relatively low mammalian acute toxicity. ${ }^{1-3}$ Furthermore, these compounds are also used as vulcanization accelerators and antioxidants in the rubber industry. ${ }^{2}$

Generally, DTCs are not considered to be highly toxic, but short-term exposure can cause eye, respiratory and skin irritation. ${ }^{4}$ The toxicological significance of such fungicides in food is related to the metabolite or its degradation product ethylenethiourea (ETU), which is known to be carcinogenic, mutagenic and teratogenic. ${ }^{5}$

*e-mail: pizzutti@quimica.ufsm.br
A variety of methods have been developed to analyze DTC residues in different crops. Many of these methods are based on acid hydrolysis of DTC in the presence of tin(II) chloride and subsequent analysis of the evolved carbon disulfide $\left(\mathrm{CS}_{2}\right)$ by different techniques such as UV-Vis spectrophotometry, ${ }^{6,7}$ gas chromatography (GC), ${ }^{8-12}$ or headspace GC. ${ }^{13}$ Detection techniques for some individual DTCs, using capillary electrophoresis $(\mathrm{CE})^{14}$ or liquid chromatography (LC) are also available. ${ }^{9,15}$ Other less common techniques, such as voltammetry, ${ }^{8}$ flow injection analysis (FIA) ${ }^{16,17}$ and immunoassay, ${ }^{18}$ have also been used for the determination of this class of pesticides, but have also never found widespread applications in routine laboratories.

Lettuce is considered the main leafy vegetable crop in Brazil. ${ }^{19}$ The maximum residue level (MRL) for DTCs in lettuce was decreased from 6 to $0.05 \mathrm{mg} \mathrm{CS}_{2} \mathrm{~kg}^{-1}$ and 
withdrawn from the National Sanitary Surveillance Agency (ANVISA) list in 2005. ${ }^{20}$ Nowadays, the Brazilian MRL for DTC's in lettuce is $3 \mathrm{mg} \mathrm{CS} \mathrm{kg}^{-1}$, only from permitted use of methiram. ${ }^{21}$

DTCs are still one of the most frequently detected pesticides in the European Union and this pesticide class also showed the highest frequency of exceedances of maximum residue limits (MRLs) in the monitoring program of pesticide residues in food products. ${ }^{1}$ In Brazil, Jardim and Caldas ${ }^{20}$ analyzed a total of 13,556 samples of fruits and vegetables between 2001 and 2010. Dithiocarbamates were the pesticides that most frequently exceeded the Brazilian MRL during that period. According to the report of Brazilian National Monitoring Program on Pesticide Residues (PARA), ANVISA (2012)22 $45 \%$ of lettuce samples showed unsatisfactory results for DTC.

The DTCs represent one of the most complex pesticides group to be determined due to their low stability in vegetable matrices and low solubility in water or polar organic solvents. The most widely used method to analyze DTC residues in fruits and vegetables is the analysis of $\mathrm{CS}_{2}$. Although it is time consuming, UV-Vis spectrophotometric analysis is still relatively frequently used worldwide to determine residues of DTCs. For instance, gas chromatographic with electron capture detector (GC-ECD) is still the analytical technique employed by the EU Reference Laboratory for Residues of Pesticides-Single Residue Methods (EURL-SRM) for dithiocarbamate determination. ${ }^{23}$ Therefore, the purpose of this study was to compare critically and statically the performance of the gas chromatographic methods using three different detection systems (electron capture detection (ECD), pulsed flame photometric detection (PFPD) and mass spectrometry (MS)) with a UV-Vis spectrophotometric method for the determination of DTCs in lettuce.

\section{Experimental}

\section{Chemicals and reagents}

Iso-octane, pesticide grade (Lab-scan Analytical Sciences, Dublin, Ireland), toluene, pesticide grade (Mallinckrodt, St. Louis, USA), solution of tin(II) chloride $1.5 \%$ in $4 \mathrm{~mol} \mathrm{~L}^{-1}$ hydrochloric acid (Boom, Meppel, The Netherlands), hydrochloric acid (Nuclear, São Paulo, Brazil), tin(II) chloride (Nuclear, São Paulo, Brazil), copper acetate (Vetec, Rio de Janeiro, Brazil), diethanolamine (Nuclear, São Paulo, Brazil), ethanol (Vetec, Rio de Janeiro, Brazil), sodium hydroxide (Merck, Darmstadt, Germany) and lead acetate (Vetec, Rio de Janeiro, Brazil) were used. Pesticide reference material of thiram (99\% purity) and carbon disulfide (99.9\%) were purchased from Dr. Ehrenstorfer (Augsburg, Germany).

\section{Reference materials and solutions}

For the spectrophotometric method the following solutions were prepared: tin(II) chloride $1.5 \%(\mathrm{~m} / \mathrm{v})$ in hydrochloric acid $\left(4 \mathrm{~mol} \mathrm{~L}^{-1}\right)$, lead acetate aqueous solution $30 \%(\mathrm{~m} / \mathrm{v})$, sodium hydroxide solution $\left(2.5 \mathrm{~mol} \mathrm{~L}^{-1}\right)$ and a solution of complexing reagent ( $25 \mathrm{~g}$ of diethanolamine and $12 \mathrm{mg}$ of copper acetate in $250 \mathrm{~mL}$ of ethanol).

A carbon disulfide stock solution $\left(1000 \mu \mathrm{g} \mathrm{mL}^{-1}\right)$ was prepared in iso-octane (chromatographic method) or ethanol and complexing reagent (spectrophotometric method) and stored at $-18{ }^{\circ} \mathrm{C}$.

The stock solution of thiram $\left(1000 \mu \mathrm{g} \mathrm{mL} L^{-1}\right.$, solution A) was prepared in toluene and it was diluted with iso-octane to produce the working analytical solution $100 \mu \mathrm{g} \mathrm{mL}^{-1}$ (solution B), which was used as a spike solution for the recovery experiments in both methods. These solutions were stored at $-18{ }^{\circ} \mathrm{C}$ and were stable for one year. ${ }^{24}$

\section{Apparatus and experimental conditions}

\section{Chromatographic method}

Chromatographic analyses were carried out on a gas chromatograph model 3800 (Varian, Walnut Creek, USA) equipped with a pulsed flame photometric detector (PFPD), operated in the sulfur mode and an electron capture detector (ECD). GC-MS experiments were performed on a gas chromatograph model 3800 (Varian) coupled to a Varian Saturn 2000 ion trap detector (ITD). Both GCs were equipped with an autosampler model 8400 (Varian), a 1079 injector and a capillary column, CP-Sil 8 CB $(50 \mathrm{~m} \times 0.32 \mathrm{~mm}$ i.d. $\times 1.2 \mu \mathrm{m}$ film thickness) obtained from Varian (Middelburg, The Netherlands). The injector temperature was $250^{\circ} \mathrm{C}$; the column oven was programmed from 45 (hold for $1 \mathrm{~min}$ ) to $250{ }^{\circ} \mathrm{C}$ (hold for $0 \mathrm{~min}$ ) at $10{ }^{\circ} \mathrm{C} \mathrm{min}^{-1}$. The carrier gas was helium $(99.999 \%$ purity, from Air Liquide, France) with a constant flow-rate of $2 \mathrm{~mL} \mathrm{~min}{ }^{-1}$. The injection volume was $4 \mu \mathrm{L}$, with a split ratio of 1:10 for GC-ECD and GC-ITD-MS, and 1:15 for GC-PFPD. The detector temperatures were $300{ }^{\circ} \mathrm{C}$ and $250^{\circ} \mathrm{C}$ for the ECD and for the PFPD, respectively. The GC-ITD-MS transferline and trap were set at $230{ }^{\circ} \mathrm{C}$ and the manifold at $120^{\circ} \mathrm{C}$. For GC-ITD-MS, a selected mass range $(\mathrm{m} / \mathrm{z}, 70-80)$ was used for the acquisition mode.

\section{Spectrophotometric method}

The acid decomposition of the DTCs occurred in a $500 \mathrm{~mL}$ round-bottom three-neck boiling flask placed in 
a heating mantle. One neck of the flask was connected to a nitrogen (White Martins, Brazil) inlet tube, the second one was used to add the hydrolysis reagent (acidic tin(II) chloride solution) and the center flask neck was used to introduce the sample and to connect a reflux condenser, which was then connected to the three traps in series. The first two traps were used to remove any interference and in the third trap, $\mathrm{CS}_{2}$ reacted with the complexing reagent (Figure 1). The spectrophotometric analyses were carried out in a dual beam UV-Vis spectrophotometer (PerkinElmer, Germany) at $435 \mathrm{~nm}$, after complexation of the $\mathrm{CS}_{2}$ with diethanolamine and copper.

\section{Sample preparation and analysis}

The methods for determining DTCs are based on acidic hydrolysis to $\mathrm{CS}_{2}$ in the presence of tin(II) chloride. ${ }^{26}$ If the origin of the $\mathrm{CS}_{2}$ is known, for example by the known use of a certain DTC, an appropriate conversion factor can be used to give a result expressed as the corresponding DTC from the $\mathrm{CS}_{2}$ result. In this paper, thiram was used for the validation studies. In this case, 1 mol thiram decomposes to give $2 \mathrm{~mol} \mathrm{CS}_{2}$ (Figure 2). The molecular mass of thiram is $240 \mathrm{~g}$ and of $\mathrm{CS}_{2}$ is $76 \mathrm{~g}(2 \mathrm{~mol}=152 \mathrm{~g})$. The conversion factor is thus $240 / 152=1.58$, and the concentration of thiram $=\mathrm{CS}_{2}$ concentration $\times 1.58 .^{4}$

\section{Chromatographic method}

The blank lettuce (without DTC) used for the recovery studies were acquired from supermarkets in Amsterdam (The Netherlands) and from an organically grown products open market in Santa Maria (RS, Brazil). The samples were prepared as described below.

The lettuce leaves were coarsely cut in a food chopper and shortly homogenized. A mass of $50 \pm 0.5 \mathrm{~g}$ of blank lettuce was directly weighed in a $250 \mathrm{~mL}$ polytetrafluoroethylene (PTFE)coated, screw-capped glass bottle and for the recovery study, an appropriate volume of spike solution of thiram was added to blank lettuce. Then, $25 \mathrm{~mL}$ of iso-octane and $150 \mathrm{~mL}$ of tin(II) chloride solution in hydrochloric acid were added. The bottles were closed immediately and heated for $2 \mathrm{~h}$ in a water bath (Thermo Haake, Karlsruhe, Germany), at a temperature of $80{ }^{\circ} \mathrm{C}$, under continuous mechanical shaking. The bottles were cooled to room temperature in a cold-water bath. After cooling, $1 \mathrm{~mL}$ aliquot of the upper organic layer of each bottle was transferred to autosampler vials (by means of a Pasteur pipette) and analyzed by GC-ECD, GC-PFPD and GC-ITD-MS.

\section{UV-Vis spectrophotometric method}

A mass of $50 \pm 0.5 \mathrm{~g}$ of homogenized blank lettuce was transferred to the three-neck round-bottom flask, connected to the condenser cooled with water and to traditional in-series-three-trap reaction system. In the first two traps, were added $10 \mathrm{~mL}$ of lead acetate solution and $10 \mathrm{~mL}$ of sodium hydroxide solution, respectively, to remove possible volatile interferences, mainly $\mathrm{H}_{2} \mathrm{~S}$ and $\mathrm{SO}_{2}$. In the third trap was added $15 \mathrm{~mL}$ of complexing reagent.

For the recovery study, an appropriate volume of stock solution of thiram was added to the sample. Then, $220 \mathrm{~mL}$ of hot tin(II) chloride acid solution was added and the $\mathrm{N}_{2}$ flow and the heating mantle were turned on. After boiling for $1 \mathrm{~h}$, the system was turned off and the solution in the third trap was transferred to a $25 \mathrm{~mL}$ volumetric flask, the volume was completed with ethanol, and the absorbance was measured at $435 \mathrm{~nm}$.

\section{Preparation of analytical solutions}

\section{Chromatographic method}

Known volumes of $\mathrm{CS}_{2}$ solution $\left(40 \mu \mathrm{g} \mathrm{mL}^{-1}\right.$ in iso-octane) were transferred to clean glass vials to prepare a series of analytical solutions ranging from 0.08 to $2.0 \mu \mathrm{g} \mathrm{CS}_{2} \mathrm{~mL}^{-1}$, in iso-octane, corresponding to 0.04 to $1.0 \mathrm{mg} \mathrm{CS}_{2} \mathrm{~kg}^{-1}$ in the sample. These solutions were injected into three different GC systems to obtain the analytical curves.

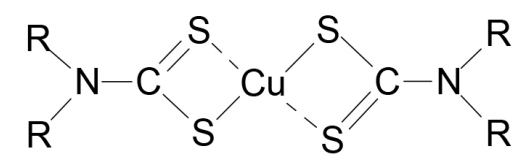

Figure 1. Reaction between $\mathrm{CS}_{2}$ and complexing reagent (diethanolamine and copper). ${ }^{25} \mathrm{R}=$ ethanol.

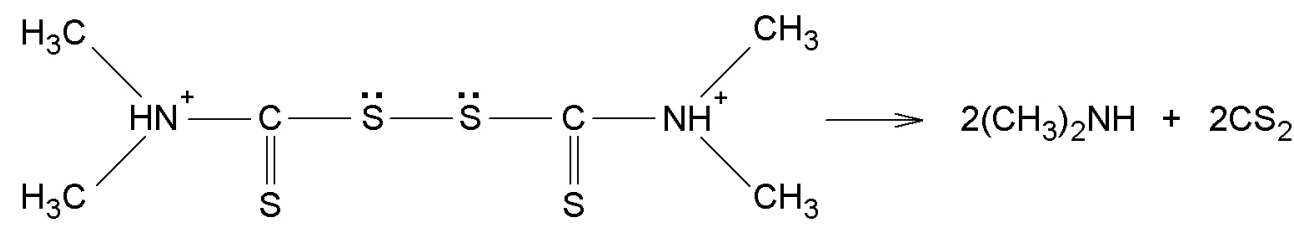

Figure 2. Reaction of thiram hydrolysis. 


\section{Spectrophotometric method}

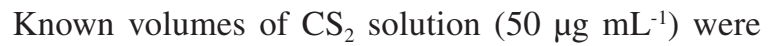
transferred to $25 \mathrm{~mL}$ volumetric flasks, together with $15 \mathrm{~mL}$ of complexing solution and the final volume was added up with ethanol. The solutions were allowed to stand for $15 \mathrm{~min}$ and the absorbance was measured with the spectrophotometer UV-Vis. Two analytical curves were constructed, in the range from 0.4 to 2.2 and from 2.2 to $8.9 \mu \mathrm{g} \mathrm{CS}_{2} \mathrm{~mL}^{-1}$, corresponding to 0.2 to 1.0 and 1.0 to $4.4 \mathrm{mg} \mathrm{CS}_{2} \mathrm{~kg}^{-1}$ in the sample, respectively.

\section{Method validation procedure}

The following parameters were evaluated: linearity of analytical curves, limits of detection (LOD) and quantification (LOQ), precision (repeatability and intermediate precision) and trueness, determined as recovery percentage.

\section{Chromatographic methods}

The linearity of the analytical curve was evaluated by injecting six times each analytical solution at five concentrations in the range of 0.08 to $2.0 \mu \mathrm{g} \mathrm{CS}_{2} \mathrm{~mL}^{-1}$, in each one of those three chromatographic systems. The estimated instrument $\mathrm{LOD}_{\mathrm{i}}$ from the analytical curve experiments was determined as the lowest detectable concentration giving a response with a relative standard deviation (RSD) of $<33 \%$. The repeatability and intermediate precision of the instrument's detector response were determined by the replicate analysis $(n=6)$ of analytical solutions $\left(0.1,0.2\right.$ and $\left.2.0 \mu \mathrm{g} \mathrm{CS} \mathrm{CL}^{-1}\right)$ on one day and on three different days, respectively. The repeatability of the method was determined as the relative standard deviation (RSD\%) of the recovery studies. Recovery experiments were carried out with blank lettuce, spiked with thiram at two concentrations (corresponding to 0.05 and $0.4 \mathrm{mg} \mathrm{CS}_{2} \mathrm{~kg}^{-1}$ ), with six replicates for each concentration $(n=6)$. The method $\mathrm{LOQ}_{\mathrm{m}}$ was defined as the lowest validated level with a recovery between 70 and $120 \%$ and $\mathrm{RSD}<20 \%$.

\section{Spectrophotometric method}

The linearity was evaluated by analyzing analytical solutions at seven concentrations in the range of 0.4 to $8.9 \mu \mathrm{g} \mathrm{CS}_{2} \mathrm{~mL}^{-1}$. The LOD and LOQ were determined by blank lettuce analysis $(n=6)$ and calculating three or ten times the SD of the absorbance measured, respectively. The repeatability and intermediate precision of the instruments were determined by the replicate analysis $(n=6)$ of analytical solutions $\left(0.6,1\right.$ and $\left.4 \mu \mathrm{g} \mathrm{CS}_{2} \mathrm{~mL}^{-1}\right)$ on one day and on two different days, respectively. The repeatability of the method (RSD\%) was determined by the analysis of the recovery samples. Recovery experiments were carried out on blank lettuce, spiked with thiram at concentrations corresponding to $0.4,0.8$ and $2 \mathrm{mg} \mathrm{CS}_{2} \mathrm{~kg}^{-1}$, with six replicates for each level $(n=6)$.

\section{Statistical analysis}

The results obtained from UV-Vis spectrophotometric and chromatographic methods were statistically evaluated by paired $t$-test variance, with $95 \%$ confidence interval, using software Minitab Release ${ }^{\circledR}$ 14. For all 3 detector system response was applied paired $t$-test for recoveries obtained from spike concentration $0.05 \mathrm{mg} \mathrm{CS} \mathrm{kg}^{-1}$. For results obtained from spike concentration $0.4 \mathrm{mg} \mathrm{CS}_{2} \mathrm{~kg}^{-1}$, the comparison was between both analytical techniques.

\section{Results and Discussion}

The UV-Vis spectrophotometric and chromatographic methods have been fully optimized for various crops in previous studies. ${ }^{2}$ In this study, the methods were validated for lettuce and critically and statically compared as to sensitivity and selectivity.

\section{Method validation and performance}

Table 1 shows the results of the linearity studies, the estimated $\mathrm{LOD}_{i}$ and $\mathrm{LOQ}_{\mathrm{i}}$ based on repeated analysis of $\mathrm{CS}_{2}$ analytical solutions which were analyzed by chromatographic and spectrophotometric methods.

All methods showed a very satisfactory linearity, with $r^{2}>0.99 .{ }^{27,28}$ All three chromatographic methods showed the same detectability, and thus the same LODs and LOQs (Table 1), and all three were more sensitive than the UV-Vis spectrophotometric method.

The chromatographic detection systems proved to have no significant matrix effect, that is the difference in detector response between the analytical solutions in organic solvent and those prepared in blank matrix extract did not differ by more than $20 \%$. This is true, provided that a clean injector liner with new carbofrit is first deactivated by some sample extract injections.

The relative selectivity of the three chromatographic detectors can be observed from the chromatograms (Figure 1) obtained with blank matrix extracts and the same extract redissolved in calibration solutions ("standard in matrix extracts" or "matrix-matched calibration").

Based on the number of peaks appearing in the blank extract chromatograms, the PFPD was the most selective detector and ECD the least selective. However, the 
Table 1. Linearity, LOD and LOQ data of $\mathrm{CS}_{2}$ analytical solutions analyzed by chromatographic and spectrophotometric methods

\begin{tabular}{lcccccc}
\hline Method & $\begin{array}{c}\text { Linear range / } \\
\left(\mu \mathrm{g} \mathrm{CS}_{2} \mathrm{~mL}^{-1}\right)\end{array}$ & Slope & Intercept & $\mathrm{r}^{2}$ & $\mathrm{LOD} /\left(\mathrm{mg} \mathrm{kg}^{-1}\right)$ & $\mathrm{LOQ} /\left(\mathrm{mg} \mathrm{kg}^{-1}\right)$ \\
\hline GC-ECD & & 19.908 & 1.194 & 0.9954 & 0.02 & 0.05 \\
GC-PFPD & $0.08-2.0$ & 20.207 & 0.228 & 1.0000 & 0.02 & 0.05 \\
GC-ITD-MS & & 9009.4 & 65.865 & 0.9999 & 0.02 & 0.05 \\
\hline \multirow{2}{*}{ Spectrophotometric } & $0.4-2.2$ & 0.0511 & -0.0191 & 0.9955 & 0.28 & 0.40 \\
& $2.2-8.9$ & 0.0716 & 0.0699 & 0.9995 & \\
\hline
\end{tabular}

GC-ECD: gas chromatographic electron capture detector; GC-PFPD: gas chromatographic pulsed flame photometric detector; GC-ITD-MS: gas chromatographic ion trap detector mass spectrometry; LOD: limit of detection; LOQ: limit of quantification.

chromatographic resolution of both methods was always sufficient due to the optimized capillary GC conditions.

The flame pulsation in the PFPD improved selectivity and sensitivity and this is an advantage, even compared with GC-ITD-MS, because that detection system does not have such a good sensitivity for low masses, like for $\mathrm{CS}_{2}(\mathrm{~m} / \mathrm{z}, 76)$. However, with GC-ITD-MS it was possible to confirm unequivocally the identity of the $\mathrm{CS}_{2}$ with the isotope mass of 78. When the GC-ECD was used, many interferences and negative peaks were observed (Figure 3).

The MS (ITD) detector was less selective (more generic) than the PFPD, but due to the mass spectrometric information, it is the most specific detector, due to the measurement of mass 76 and the confirmation mass of 78 at the typical isotopic ratio of 10:1. This confirmation is only possible from the $0.2 \mu \mathrm{g} \mathrm{mL} \mathrm{m}^{-1}$ concentration on, which corresponds with a method sample concentration of $0.1 \mathrm{mg} \mathrm{kg}^{-1}$.

After determining the estimated method $\mathrm{LOD}_{\mathrm{m}}$ and $\mathrm{LOQ}_{\mathrm{m}}$ (via dividing the instrument LOD and LOQ by a concentration factor of 2), the recovery study was performed at 3 spike concentrations with the lowest spike level being equal to the expected achievable (target) $\mathrm{LOQ}_{\mathrm{m}}$. The repeatability and intermediate precision of the detector's response were tested and appeared to be very satisfactory, as shown in Table 2.

The average recoveries and relative standard deviations (RSDs) obtained with chromatographic and spectrophotometric methods are shown in Table 3. For the chromatographic methods, the blank lettuce was fortified with thiram solution with corresponding concentrations of 0.05 and $0.4 \mathrm{mg} \mathrm{CS}_{2} \mathrm{~kg}^{-1}$. The recoveries are in the range of 88.9 to $107.4 \%$, with RSD ranging from 2.8 to $15.9 \%$, and are more than satisfactory to meet the method validation performance criteria is as to accuracy and precision of the analytical methods. The results in Table 3 demonstrate that only the repeatability of the GC-ECD was somewhat lower than the other methods, resulting in RSDs values exceeding $10 \%$, but still below the required $20 \%$. For the

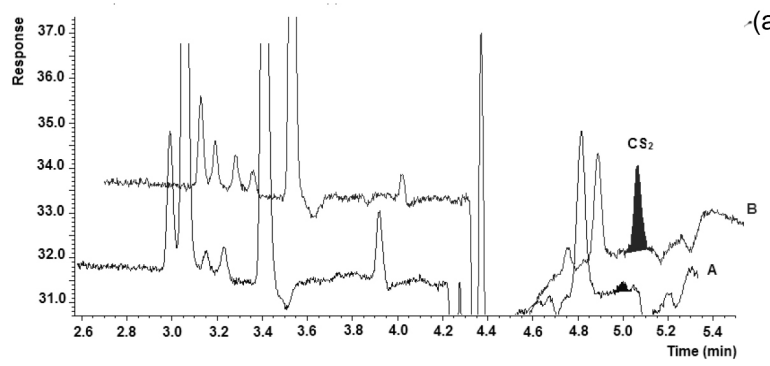

(a)
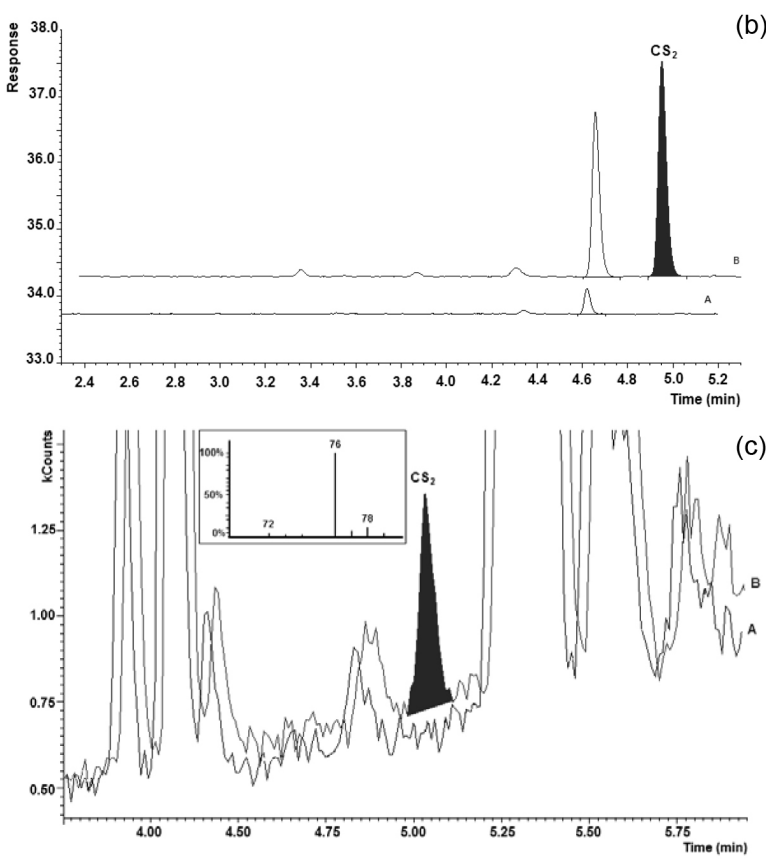

Figure 3. Chromatograms of blank lettuce extract (A) and lettuce extract spiked at $0.05 \mathrm{mg} \mathrm{CS}_{2} \mathrm{~kg}^{-1}$ (B), obtained by (a) GC-ECD; (b) GC-PFPD; (c) GC-ITD-MS.

spectrophotometric method, the recoveries were in the range of 87.7 to $94.2 \%$, with a RSD ranging from 6.0 to $9.7 \%$, and thus also met the requirements easily.

Comparing the results from Table 3 for spike concentration of $0.4 \mathrm{mg} \mathrm{CS}_{2} \mathrm{~kg}^{-1}$, no significant differences were observed in recoveries and precision between the spectrophotometric and those three chromatographic 
Table 2. Repeatability and intermediate precision of the instruments at three spiking concentrations

\begin{tabular}{lccc}
\hline Instrument & $\begin{array}{c}\text { Concentration / } \\
\left(\mu \mathrm{g} \mathrm{CS}_{2} \mathrm{~mL}^{-1}\right)\end{array}$ & $\begin{array}{c}\text { Repeatability } \\
(\mathrm{RSD}) / \%\end{array}$ & $\begin{array}{c}\text { Intermediate } \\
\text { precision } \\
(\mathrm{RSD}) / \%\end{array}$ \\
\hline GC-ECD & 0.1 & 7.7 & 3.2 \\
& 0.2 & 7.6 & 3.3 \\
GC-PFPD & 2.0 & 5.0 & 5.3 \\
\hline & 0.1 & 14.6 & 11.2 \\
& 0.2 & 14.6 & 10.0 \\
GC-ITD-MS & 2.0 & 11.9 & 3.1 \\
\hline & 0.1 & 1.2 & 3.2 \\
Spectrophotometer & 0.2 & 2.8 & 4.7 \\
UV-Vis & 2.0 & 6.7 & 4.2 \\
\hline
\end{tabular}

GC-ECD: gas chromatographic electron capture detector; GC-PFPD: gas chromatographic pulsed flame photometric detector; GC-ITD-MS: gas chromatographic ion trap detector mass spectrometry; RSD: relative standard deviation.

Table 3. Recoveries and relative standard deviations (\%), for different spike concentrations, obtained by GC-ECD, GC-PFPD, GC-ITD-MS and UV-Vis spectrophotometric methods

\begin{tabular}{lccc}
\hline Method & $\begin{array}{c}\text { Spike level / } \\
\left(\mathrm{mg} \mathrm{CS}_{2} \mathrm{~kg}^{-1}\right)\end{array}$ & $\begin{array}{c}\text { Recovery } \\
\text { average } \\
(\mathrm{n}=6) / \%\end{array}$ & RSD / \% \\
\hline GC-ECD & 0.05 & 88.9 & 15.9 \\
\hline GC-PFPD & 0.4 & 107.4 & 2.8 \\
\hline GC-ITD-MS & 0.05 & 93.9 & 9.6 \\
\hline & 0.4 & 92.8 & 5.0 \\
\hline Spectrophotometric & 0.05 & 94.0 & 9.7 \\
UV-Vis & 0.4 & 97.4 & 8.1 \\
\hline
\end{tabular}

GC-ECD: gas chromatographic electron capture detector; GC-PFPD: gas chromatographic pulsed flame photometric detector; GC-ITD-MS: gas chromatographic ion trap detector mass spectrometry; RSD: relative standard deviation.

methods (excepted to GC-ECD). The results demonstrated that the spectrophotometric method, although less sensitive, maintains the ability to analyze DTCs with good precision and accuracy. To achieve a lower $\mathrm{LOD}_{\mathrm{m}}$ and $\mathrm{LOQ}_{\mathrm{m}}$ applying the UV-Vis spectrophotometric method, instead of $50 \mathrm{~g}$ sample, a higher sample amount could be taken.

\section{Statistical analysis}

The results of $p$-value from Paired $t$-test for chromatographic method was 0.005522 , showing that difference among those $3 \mathrm{GC}$ detectors is not statistically significant. The $p$-value of 0.02612 obtained from spike concentration of $0.4 \mathrm{mg} \mathrm{CS} \mathrm{kg}^{-1}$, demonstrated not statistically significant differences between techniques. However, GC-ECD results showed some difference when compared with those others (GC-PFPD, GC-ITD-MS and UV-Vis spectrophotometry).

\section{Conclusions}

The results obtained from validation studies allow us to conclude that all the evaluated methods are appropriate to determine residues of DTC in lettuce. However, the chromatographic methods were simpler, faster and more sensitive, giving them an advantage over UV-Vis spectrophotometry. Additionally, the sample preparation for the chromatographic methods can be carried out simultaneously for many samples, in a simplified way and does not use toxic chemicals, like lead acetate (UV-Vis spectrophotometry). Among the chromatographic detectors, there were no significant differences responses, at concentration $0.05 \mathrm{mg} \mathrm{CS}_{2} \mathrm{~kg}^{-1}$. The GC-PFPD and GC-ITD-MS were more selective and more specific than the GC-ECD method and should be strongly recommended for routine applications in monitoring studies and for MRL enforcement purposes. However, there were no significant difference between both techniques at $0.4 \mathrm{mg} \mathrm{CS} \mathrm{kg}^{-1}$ concentration.

\section{Acknowledgments}

The authors would like to thank the UFSM, CNPq, FAPERGS/CAPES 0219/2015 and Netherlands Food and Consumer Product Safety Authority (Wageningen, The Netherlands) for the opportunity to develop this study.

\section{References}

1. López-Fernández, O.; Rial-Otero, R.; González-Barreiro, C.; Simal-Gándara, J.; Food Chem. 2012, 134, 366.

2. Crnogorac, G.; Schwack, W.; TrAC, Trends Anal. Chem. 2009, 28,40 .

3. Gonzalvez, A.; Garrigues, S.; Armenta, S.; Guardia, M.; Anal. Chim. Acta 2011, 688, 191.

4. Coldwell, M. R.; Pengelly, I.; Rimmer, D. A.; J. Chromatogr. A 2003, 984, 81 . 
5. Ripollés, C.; Sancho, J. V.; López, F. J.; Hernández, F.; J. Chromatogr. A 2012, 1243, 53.

6. Kesari, R.; Gupta, V. K.; Talanta 1998, 45, 1097.

7. Caldas, E. D.; Miranda, M. C. C.; Conceição, M. H.; Souza, L. C. K. R.; Food Chem. Toxicol. 2004, 42, 1877.

8. Mathew, L.; Reddy, M. L. P.; Rao, T. P.; Iyer, C. P.; Damodaran, A. D.; Talanta 1996, 43, 73.

9. Blasco, C.; Font, G.; Picó, Y.; J. Chromatogr. A 2004, 1028, 267.

10. Vryzas, Z.; Papadakis, E. N.; Papadopoulou-Mourkidou, E.; J. Agric. Food Chem. 2002, 50, 2220.

11. Caldas, E. D.; Conceição, M. H.; Miranda, M. C. C.; Souza, L. C. K. R.; Lima, J. F.; J. Agric. Food Chem. 2001, 49, 4521.

12. Abakerli, R. B.; Sparrapan, R.; Sawaya, A. C. H. F.; Eberlin, M. N.; Jara, J. L. P.; Rodrigues, N. R.; Fay, E. F.; Luiz, A. J. B.; Galvao, T. D. L.; Martins, D. S.; Yamanishi, O. K.; Toledo, H. H. B.; Food Chem. 2015, 188, 71.

13. Royer, A.; Ménand, M.; Grimault, A.; Communal, P. Y.; J. Agric. Food Chem. 2001, 49, 2152.

14. Lee, A. W. M.; Chan, W. F.; Yuen, F. S. Y.; Lo, C. H.; Chan, R. C. K.; Liang, Y.; Anal. Chim. Acta 1997, 339, 123.

15. Garcinuño, R. M.; Fernández-Hernando, P.; Cámara, C.; J. Chromatogr. A 2004, 1043, 225.

16. Nascimento, D. B.; Nascimento, P. C.; Gomes, H. M.; J. Agric. Food Chem. 1999, 47, 212.

17. Kubo, H.; Tsuda, Y.; Yoshimura, Y; Homma, H.; Nakazawa, H.; Anal. Chim. Acta 2003, 494, 49.

18. Queffelec, A. L.; Boisdé, F.; Larue, J. P.; Haelters, J. P.; Corbel, B.; Thouvenot, D.; Nodet, P.; J. Agric. Food Chem. 2001, 49, 1675.

19. Sala, F. C.; Costa, C. P.; Hortic. Bras. 2012, 30, 187.

20. Jardim, A. N. O.; Caldas, E. D.; Food Control 2012, 25, 607.
21. Agência Nacional de Vigilância Sanitária (ANVISA); Resolução No. 3.754, de 22 de Setembro de 2014, Adequação da Relação de Monografias dos Ingredientes Ativos de Agrotóxicos, Domissanitários e Preservantes de Madeira, Publicação Diário Oficial da União, de 23 de Setembro de 2014, p. 32.

22. Brazilian Program for Pesticide Residue Analysis in Food, 2014. http://portal.anvisa.gov.br/documents/111215/117818/ Relat\%25C3\%25B3rio\%252BPARA\%252B2011-12\%252B\%252B30_10_13_1.pdf/d5e91ef0-4235-4872-b18099610507d8d5, accessed in July 2016.

23. European Union, Reference Laboratory for Residues of Pesticides/Single Residue Methods (EURL-SRM); 2009. http://www.crl-pesticides.eu/library/docs/srm/meth_ DithiocarbamatesCs2_EurlSrm.PDF, accessed in July 2016.

24. European Commission, Directorate-General for Health and Food Safety; Guidance Document on Analytical Quality Control and Method Validation Procedures for Pesticides Residues Analysis in Food and Feed; SANTE, 2015.

25. Abakerli, R. B.; Sparrapan, R.; Sawaya, A. C. H. F.; Eberlin, M. N.; Jara, J. L. P.; Rodrigues, N. R.; Fay, E. F.; Luiz, A. J. B.; Galvão, T. D. L.; Martins, D. S.; Yamanishi, O. K.; Toledo, H. H. B.; Food Chem. 2015, 188, 71.

26. Cullen, T. E.; Anal. Chem. 1964, 36, 221.

27. Agência Nacional de Vigilância Sanitária (ANVISA); Resolução No. 899, Guia para Validação de Métodos Analíticos e Bioanalíticos, de 29 de Maio de 2003.

28. Ribani, M.; Bottoli, C. B. G.; Collins, C. H.; Jardim, I. C. S. F.; Melo, L. F. C.; Quim. Nova 2004, 27, 771.

Submitted: May 10, 2016

Published online: August 4, 2016

FAPERGS/CAPES has sponsored the publication of this article. 